\title{
Article \\ Genome-Wide Identification and Characterization of GhCOMT Gene Family during Fiber Development and Verticillium Wilt Resistance in Cotton
}

\author{
Cuicui Wu ${ }^{1,2}$, Dongyun Zuo ${ }^{1}$, Shuiping Xiao ${ }^{1,3}$, Qiaolian Wang ${ }^{1}$, Hailiang Cheng ${ }^{1}$, Limin Lv ${ }^{1}$, Youping Zhang ${ }^{1}$, \\ Pengbo $\mathrm{Li}^{2, *}$ and Guoli Song ${ }^{1, *}$
}

check for

updates

Citation: Wu, C.; Zuo, D.; Xiao, S.; Wang, Q.; Cheng, H.; Lv, L.; Zhang, Y.; Li, P.; Song, G. Genome-Wide Identification and Characterization of GhCOMT Gene Family during Fiber Development and Verticillium Wilt Resistance in Cotton. Plants 2021, 10, 2756. https://doi.org/10.3390/ plants10122756

Academic Editor: Tika Adhikari

Received: 25 October 2021

Accepted: 6 December 2021

Published: 14 December 2021

Publisher's Note: MDPI stays neutral with regard to jurisdictional claims in published maps and institutional affiliations.

Copyright: (c) 2021 by the authors. Licensee MDPI, Basel, Switzerland. This article is an open access article distributed under the terms and conditions of the Creative Commons Attribution (CC BY) license (https:/ / creativecommons.org/licenses/by/ $4.0 /)$.
1 State Key Laboratory of Cotton Biology, Institute of Cotton Research of Chinese Academy of Agricultural Sciences, Anyang 455000, China; wucuicui1982@sxau.edu.cn (C.W.); zdy041@163.com (D.Z.); shuipingxiao@163.com (S.X.); wangq11232021@163.com (Q.W.); pser2010@163.com (H.C.); 1lm0372@126.com (L.L.); zyp547550790@163.com (Y.Z.)

2 Cotton Research Institute, Shanxi Agricultural University, Yuncheng 044000, China

3 Cotton Research Institute of Jiangxi Province, Jiujiang 332105, China

* Correspondence: lipengbo@sxau.edu.cn (P.L.); songguoli@caas.cn (G.S.); Tel.: +86-372-2562377 (P.L. \& G.S.)

\begin{abstract}
Caffeic acid O-methyltransferases (COMTs) play an essential role in lignin synthesis procession, especially in the plant's phenylalanine metabolic pathway. The content of COMT genes in cotton and the relationship between their expression patterns have not been studied clearly in cotton. In this study, we have identified 190 COMT genes in cotton, which were classified into three groups (I, II and III), and mapped on the cotton chromosomes. In addition, we found that 135 of the 190 COMT genes result from dispersed duplication (DSD) and whole-genome duplication (WGD), indicating that DSD and WGD were the main forces driving COMT gene expansion. The $\mathrm{Ka} / \mathrm{Ks}$ analysis showed that GhCOMT43 and GhCOMT41 evolved from GaCOMT27 and GrCOMT14 through positive selection. The results of qRT-PCR showed that GhCOMT13, GhCOMT28, GhCOMT39 and GhCOMT55 were related to lignin content during the cotton fiber development. GhCOMT28, GhCOMT39, GhCOMT55, GhCOMT56 and GhCOMT57 responded to Verticillium Wilt (VW) and maybe related to VW resistance through lignin synthesis. Conclusively, this study found that GhCOMTs were highly expressed in the secondary wall thickening stage and VW. These results provide a clue for studying the functions of GhCOMTs in the development of cotton fiber and VW resistance and could lay a foundation for breeding cotton cultivates with higher quantity and high resistance to VW.
\end{abstract}

Keywords: cotton; caffeic acid O-methyltransferase (COMT); evolution; expression patterns; fiber development; VW

\section{Introduction}

Cotton (Gossypium) is currently one of the most important economic crops globally, and it also occupies a vitally important position in economy of the China. Cotton fiber is an essential natural plant fiber with high applications in the modern textile industry [1]. Cotton fiber is developed from the single cell of ovule epidermis, and it is the most extended plant cell found so far, which is different from the general phloem fiber [2]. The process of cotton fiber development can be divided into five stages: fiber initiation stage ( -3 DPA3 DPA), rapid cell growth stage (primary wall synthesis) (2-20 DPA), transitional period (16-20 DPA), secondary wall thickening stage (16 45DPA) and dehydration maturity stage (45-50 DPA) [3,4]. The cotton fiber is mainly made of cellulose, which account for $93-95 \%$ of the dry weight, and the rest are companions of the fiber [5]. Therefore, cotton fiber is important for studying cell elongation and cell wall growth of cotton.

Lignin is a polyphenolic polymer surrounded by wood fibers, other tube bundle cells and thick-walled cell walls. It is the most prominent secondary substance in plants, and the total amount of lignin is the second-largest organic matter after cellulose [6]. Lignin can 
increase the mechanical strength of plant cells and tissues, help in water transport in plant tissues and improve plants' resistance to diseases and insect pests $[7,8]$. In plants, there are two kinds of $O$-methyltransferases in the lignin biosynthesis pathway, namely caffeoyl coenzyme A 3-O-methyltransferase (CCOAOMT) and caffeoyl-CoA 3-O-methyltransferase (COMT) $[9,10]$. COMT is responsible for $O$-methylation of the C5 position of the phenol ring [10] and, therefore, plays a significant role in the lignin biosynthesis pathway [9]. For example, AtCOMT is a multifunctional enzyme responsible for the biosynthesis of lignin and flavonoids in plants with caffeic acid as the natural substrate [11,12]. Moreover, COMT catalyzes Melatonin production from N-acetyl 5-hydroxytryptamine [13,14]. Overexpression of TaCOMTs can also contribute to plants growth [15].

Few functional studies of COMT genes in some plant species [16-20] have revealed that COMT genes have particular impacts in different biological functions. Recently, the complete genome sequencing of two tetraploid species G. hirsutum [21-25] and two diploid cotton species G. raimondii [26,27] and G. arboretum [28] enabled analyzing the characteristics and functions of cotton COMT genes. There are two studies on the COMT genes in the Gossypium species [29,30]. GhCOMT1 (GenBank accession number FJ479708), GhCOMT2 (GenBank accession number FJ479709) and GhCOMT3 (GenBank accession number FJ848869) were highly expressed in roots and stems of cotton but not in leaves and cotyledons [29]. Another study showed that $O$-methyltransferase genes have multiresponses to salt stress and fiber development in Gossypium species [30]. However, our study is mainly based on bioinformatics analysis of G. hirsutum, G. barbadense, G. arboretum and G. raimondii, which contained the identification of COMT family genes, chromosome location, conservative domain and collinear analysis and analysis of fiber development and Verticillium wilt response from qRT-PCR results. Thus, this study is of great significance for the study of COMT family genes for cotton fiber development and VW.

\section{Methods}

2.1. Identification of COMT Genes in Cotton and Subcellular Localization Prediction of GhCOMTs in G. hirsutum

The genomic, CDS and protein sequences of G. hirsutum (HAU), G. arboreum (CRI), G. barbadense (ZJU) and G. raimondii (JGI) were downloaded from Cotton Functional Genomics Database (Cotton FGD) (https://cottonfgd.org/, accessed on 10 July 2021). Genome data of $A$. thaliana [31] were downloaded for comparative analysis of COMT genes, while the Hidden Markov Model (HMM) file of the COMT conservative domain (PF00891) was obtained from the Pfam database (http:/ / pfam.xfam.org, accessed on 10 July 2021). Then, we used HMMER3.0 software (http:/ / www.hmmer.org/, accessed on 10 July 2021) with an e-value of $1 \times 10^{-5}$ as the threshold to acquire COMT protein sequences, which included PF00891. All putative COMTs were further identified by SMART (http: / / smart.embl-heidelberg.de/, accessed on 10 July 2021), and the genes containing a COMT domain were employed for further analysis. The subcellular location of GhCOMTs was predicted by WOLF-PSORT (https: / / wolfpsort.hgc.jp/, accessed on 10 July 2021) [32] and CELLO ver.2.5 (http:/ / cello.life.nctu.edu.tw / , accessed on 10 July 2021) [33].

\subsection{Construction of Phylogenetic Tree of COMT Family}

Multi-sequence alignment of all COMT protein sequences was carried out using Clustal X [34], and phylogenetic trees were constructed using the MEGA software proximity method (version 6.0) (Neighbor-Joining, NJ) [35] with the calibration parameter Bootstrap being set to 1000. The online software Evolview (https:/ / www.omicsclass.com/article/671, accessed on 10 July 2021) was used to modify the evolutionary tree.

\subsection{Chromosome Location, Collinearity Analysis and Gene Duplication Analysis}

Genomic sequences, CDS sequences, and GFF (general feature format) information of G. hirsutum, G. arboreum and G. raimondii were downloaded from Cotton Functional Genomic Database (CottonFGD) (https: / / cottonfgd.org/, accessed on 10 July 2021). The 
position of COMT members on chromosomes was analyzed and drawn by MapChart2.2 software. To determine whether the COMT gene family expanded through segmental duplication or tandem duplication events, a collinear analysis was completed with an all-toall BLAST array (E-value of $1 \times 10^{-5}$ ) in the MCScan program [36]. They were visualized using TBtools software, and the parameter for filtering genes in the small collinearity block was set to 40 [37].

\subsection{Gene Duplication and Synonymous and Non-Synonymous Substitution Rate}

Gene duplication in cotton species was executed by DupGen_finder (https:/ / github. com/qiao-xin/DupGen_finder, accessed on 10 July 2021). Selection pressure analysis was performed by calculation of Ka (non-synonymous substitution rate) and Ks (synonymous substitution rate) values of homologous genes using KaKs_Calculator 2.0 software [38], with NG methods to calculate the Ks/Ka ratios of homologous gene pairs.

\subsection{Gene Structure and Conservative Protein Motif}

The exon-intron structure of GhCOMTs family genes was analyzed with the online Gene Structure Display Server (GSDS) [39] (http:/ / gsds.cbi.pku.edu.cn, accessed on 10 July 2021) by inputting gene annotation GFF files. The MEME program [40] was used to analyze conserved motifs of entire GhCOMT protein sequences with the following parameters: a maximum number of ten motifs, an optimum motif width of 6 to 50, the motif number distributed in sequences was set to 0 or 1 and the remainder of the parameters was set to system defaults. The phylogenetic tree, along with gene structure, and conserved protein motifs were combined and visualized by TBtools [37].

\subsection{Analysis of COMT Gene Promoters in the Cotton}

The elements in the promoter fragments of the GhCOMT genes (1500 bp upstream region of the initiation codon "ATG" of GhCOMTs) were identified to perform the cis-acting element analysis with the online program PlantCARE (http:/ / bioinformatics.psb.ugent. be/webtools / plantcare/html/, accessed on 10 July 2021). The promoters of GhCOMTs with specific expression pattern were referred as target sequences. Homer [41] was used to identify the specific cis-elements in the target sequences.

\subsection{Analysis of Expression Pattern of GhCOMTs during Fiber Development}

The TM- 1 ovules at -3 DPA, -1 DPA, 0 DPA, 1 DPA, 3 DPA and 5 DPA and fibers at 7 DPA, 10 DPA, 15 DPA, 20 DPA and 30 DPA were collected. Three biological repeats were collected in each stage. All samples were immediately frozen in liquid nitrogen and stored at $-80{ }^{\circ} \mathrm{C}$. Total RNAs were extracted by the Total RNA Extraction Kit (R1200) (Beijing Solarbio Science \& Technology Co. Ltd., Beijing, China) from all the samples for transcriptomic analysis. RNA samples were used as templates for reverse transcription with the PrimeScript RT Reagent kit (Takara, Japan) to obtain cDNA libraries. The cDNA libraries were subjected to 101-cycle paired-end sequencing on an Illumina HiSeq 4000 platform at Berry Genomics (Beijing, China). The data were normalized, and FPKM (Fragments per kilobase of transcript per million) was obtained (Table S1). The GhCOMTs with an FPKM > 1 at least in one stage of the ovule and fiber development were employed for further analysis. The genes were classified into specific and nonspecific expression by the method used in previous research [42]. The expression heatmaps were visualized by TBtools software [37].

\subsection{RNA Extraction and Real-Time Quantitative PCR Analysis for Gene Expression}

G. hirsutum cultivars TM-1 were grown in the Institute of Cotton Research's experimental farm, Chinese Academy of Agricultural Sciences, Anyang, Henan, China, in 2020. The total RNA samples of TM-1 ovule and fiber were extracted with the RNAprep Pure Plant Kit by (Tiangen, Beijing, China). The RNA samples were treated with DNase1 to eliminate the genomic DNA contamination. RNA concentration and integrity were observed on 
Nano Drop 2000 spectrophotometer (Thermo scientific, Waltham, MA, USA) and then 1\% agarose gel electrophoresis was used to detect the extraction quality of RNA. An amount of $2 \mu \mathrm{g}$ RNA was reversely transcribed into cDNA with the PrimeScript RT Reagent kit (Takara, Japan) and stored in the refrigerator at $-20^{\circ} \mathrm{C}$. Specific primers were designed according to the CDS sequence of the GhCOMT genes on the primer-blast of NCBI website. The G. hirsutum histone-3 gene (GhHis3, GenBank accession no. AF024716) was used as an internal reference [43], and the primer sequences of GhCOMT genes were shown in Additional file 1: Table S2. qRT-PCR was performed with ABI 7500 fast Real-Time PCR system (Applied Biosystems, Waltham, MA, USA). Gene expression data were obtained with three biological replicates. The total reaction system was $20 \mu \mathrm{L}$, including $2 \times$ SYBR Premix Ex Taq $10 \mu \mathrm{L}, 10 \mathrm{mmol} \cdot \mathrm{L}^{-1}$ forward primer $0.5 \mu \mathrm{L}, 10 \mathrm{mmol} \cdot \mathrm{L}^{-1}$ reverse primer $0.5 \mu \mathrm{L}$, cDNA template $1 \mu \mathrm{L}$ and dd $\mathrm{H}_{2} \mathrm{O} 8 \mu \mathrm{L}$. PCR amplification conditions were set at $95^{\circ} \mathrm{C}, 30 \mathrm{~s} ; 95^{\circ} \mathrm{C}, 5 \mathrm{~s}$; and $60^{\circ} \mathrm{C}$ for $20 \mathrm{~s}$. Moreover, the relative quantitative analysis of gene expression was carried out by the $2^{-\Delta \Delta \mathrm{Ct}}$ method with three independent replicates [44].

\subsection{Fungal Culture, Infection of Plants and Disease Assessment}

$V d 086$, a virulent defoliating $V$. dahliae strain, was isolated from cotton in Anyang, China, and grown on PDA medium at $25^{\circ} \mathrm{C}$ for 3 days. Mycelia were collected and cultured in Czapek's medium for 3 days at $25^{\circ} \mathrm{C}$ with shaking ( $200 \mathrm{rpm}$ ).

Cotton seedlings (TM-1) with one true-leaf unfolded were inoculated by dipping the roots into $V d 086$ spore suspension containing $1 \times 10^{7}$ conidia $\mathrm{mL}^{-1}$ [45]. The cotton root was cut with a blade and placed in a petri dish, then poured in the $10 \mathrm{~mL}$ spore suspensions. The control was poured into $10 \mathrm{~mL}$ sterile distilled water. The plants inoculated with $V$. dahliae were cultured in a growth chamber at $25^{\circ} \mathrm{C}$ under a $16 \mathrm{~h} \mathrm{light} / 8 \mathrm{~h}$ dark cycle. The total number of inoculated plants (cotyledons and true leaves wilting or yellowing) reached more than 10. The roots, stems, cotyledons and true leaves of diseased plant and CK (5 plants, respectively, no visible wilting or yellowing symptoms) were harvested with three biological replicates to extract the total RNA, which was used to analyze the expression level of VW.

\section{Results}

3.1. Identification of COMT Family Members in Cotton and Protein Physico-Chemical and Biochemical Characteristics of GhCOMTs

The COMT family genes of cotton were identified by Blastp and Pfam and renamed according to the position of the genes on the chromosome. Among them, upland cotton has 57 COMT genes members named GhCOMT1 GhCOMT57; G. barbadense has the most genes and are named GbCOMT1 GbCOMT60; G. arboretum COMT members are named as GaCOMT1 GaCOMT35; and G. raimondii COMTs are named GrCOMT1 GrCOMT35 (Additional file 1: Table S3).

We analyzed the biochemical properties of GhCOMTs (Additional file 1: Table S3). The codin sequence lengths of these genes were between $720 \mathrm{bp}$ (GhCOMT11) to $1158 \mathrm{bp}$ (GhCOMT50); they coded 239 (GhCOMT11) to 385 (GhCOMT50) amino acid molecules; their relative molecular masses were between $26.81 \mathrm{kD}$ (GhCOMT11) and $43.30 \mathrm{kD}$ (GhCOMT50); and the isoelectric points of these proteins ranged between 4.745 (GhCOMT8) and 7.553 (GhCOMT27). The subcellularlocation prediction of GhCOMTs showed that most of the proteins were located in the cell cytoplasm. Seven proteins were in the periplasmic space. GhCOMT16 and GhCOMT17 were in the cytoplasm and periplasmic; GhCOMT25, GhCOMT26 and GhCOMT52 were in the cytoplasm and periplasmic space (Additional file1: Table S3).

\subsection{Phylogenetic Analysis of COMT Genes in Cotton}

The phylogenetic tree was constructed using the amino acid sequences of all the COMT proteins between cotton and Arabidopsis thaliana (Figure 1). The phylogenetic tree showed that all COMT proteins were divided into three groups. The first groups were divided into 
three subgroups and had 73 members. The third group was divided into four subgroups and contained 100 members. All COMTs of Arabidopsis thaliana were distributed in the group III, indicating that COMT genes between Arabidopsis and cotton differed significantly.

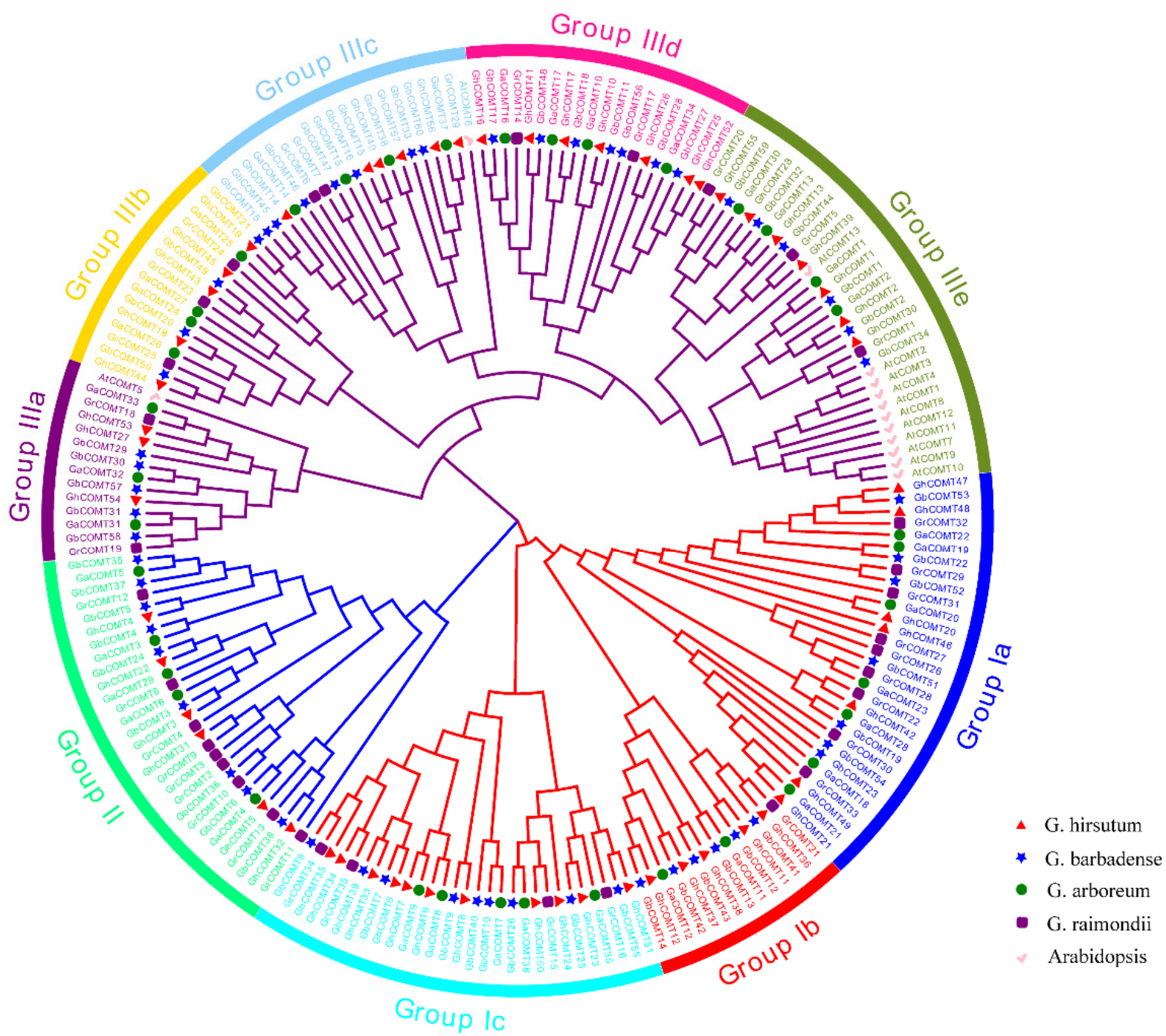

Figure 1. Phylogenetic analysis and subfamily classification of the COMT genes in Arabidopsis (AtCOMT), G. hirsutum(GhCOMT), G. barbadense(GbCOMT), G. arboreum(GaCOMT) and G. raimondii (GrCOMT). The phylogenetic tree was constructed with MEGA 6.0 using the neighbor-joining model with 1000 bootstrap replicates. All 190 COMTs were divided into nine subgroups, which were highlighted by different colors.

\subsection{Chromosomal Distribution of Cotton COMT Genes}

The analysis of chromosomal location was performed by TBtools software [37]. Fiftysix GhCOMTs, thirty-eight GaCOMTs and thirty-five GrCOMTs were positioned on their respective chromosomes (Figure 2). In G. hirsutum (AtDt genome), unexpectedly, there were no COMT genes in At02, At07, Dt03, Dt05 and Dt11 chromosomes (Figure 2). The distribution of genes in Dt sub-genome (28 genes) was equal with the genes in At subgenome. The maximum number of genes in a chromosome was eight in Dt10 followed by six both in At12 and Dt12. At05, At06, At11, At13, Dt01, Dt06 and Dt09 only had one COMT gene; At01, At09, Dt02, Dt07, Dt08 and Dt13 had two COMT genes; At03, At08 and Dt04 had three COMT genes; and At04 and At10 had four COMT genes. In G. arboretum (A-genome) (Figure 2), 38 COMT genes were mapped in all chromosomes except chr01 and chr06. Chr10 harbored 11 COMT genes, which were the highest per chromosome, followed by chr12 and chr03 with seven and four genes, respectively. The minimum number of 
genes located in a chromosome was one in chr05 and chr11, respectively. In G. raimondii (D genome), chr11 was mapped with 12 genes followed by chr05 and chr08 with six genes. The minimum number of genes in a chromosome was one in chr2, chr6 and chr10, respectively. There was no COMT family members identified in chr01, chr07 and chr09 (Figure 2).

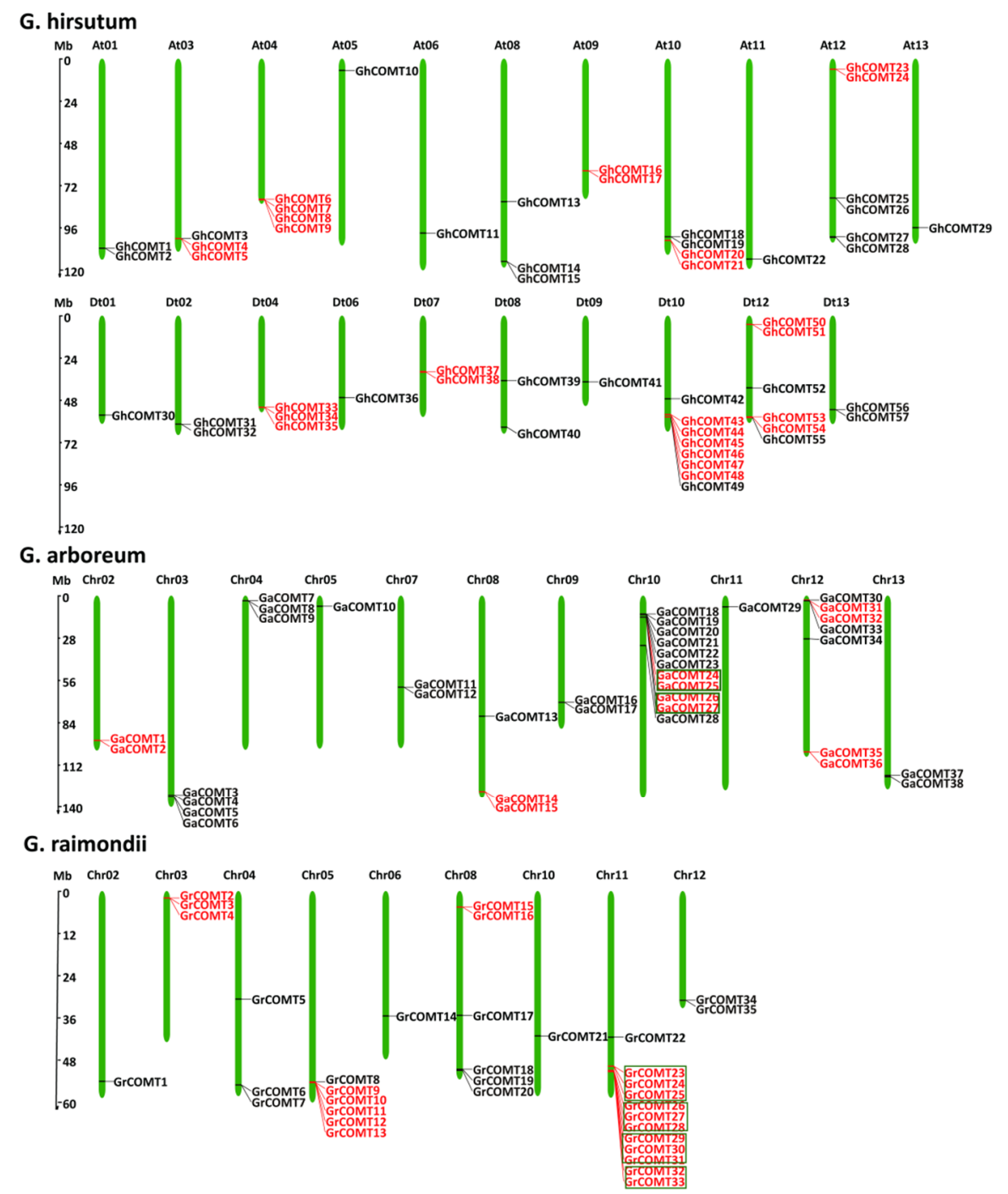

Figure 2. Chromosomal locations of COMT gene family in G. hirsutum, G. arboreum and G. raimondii. The chromosome name is above each chromosome, and the red lines on the chromosome are tandem genes. The green box separates multiple sets of tandem genes.

\subsection{Gene Structure and Conserved Motifs Analysis of GhCOMT}

The GhCOMT gene structure helps to further investigate phylogenetic relationships (Figure 3). The GhCOMT family was divided into four groups. Within the same group, most members had similar exon and intron quantities. For example, except GhCOMT24 and GhCOMT35 which contained four and three exons, the other members in group I had two exons. In addition, 10 of the 11 members in the group had 10 motifs, and only GhCOMT24 had eight motifs. In group II, six members contained 10 motifs and 2 exons, in which the introns lengths were different. Twelve GhCOMT genes were present in group III, in which GhCOMT11 and GhCOMT36 had six motifs. In accordance with that, GhCOMT11 and GhCOMT36 contained four exons and five exons. Group IV had the most members28-which contained five subgroups. GhCOMT14, GhCOMT26 and GhCOMT57 had eight, seven and seven motifs, and other members contained 9 or 10 motifs. GhCOMT10 consisted of seven exons, which is the maximum among the all GhCOMTs. 
a

$\mathrm{b}$

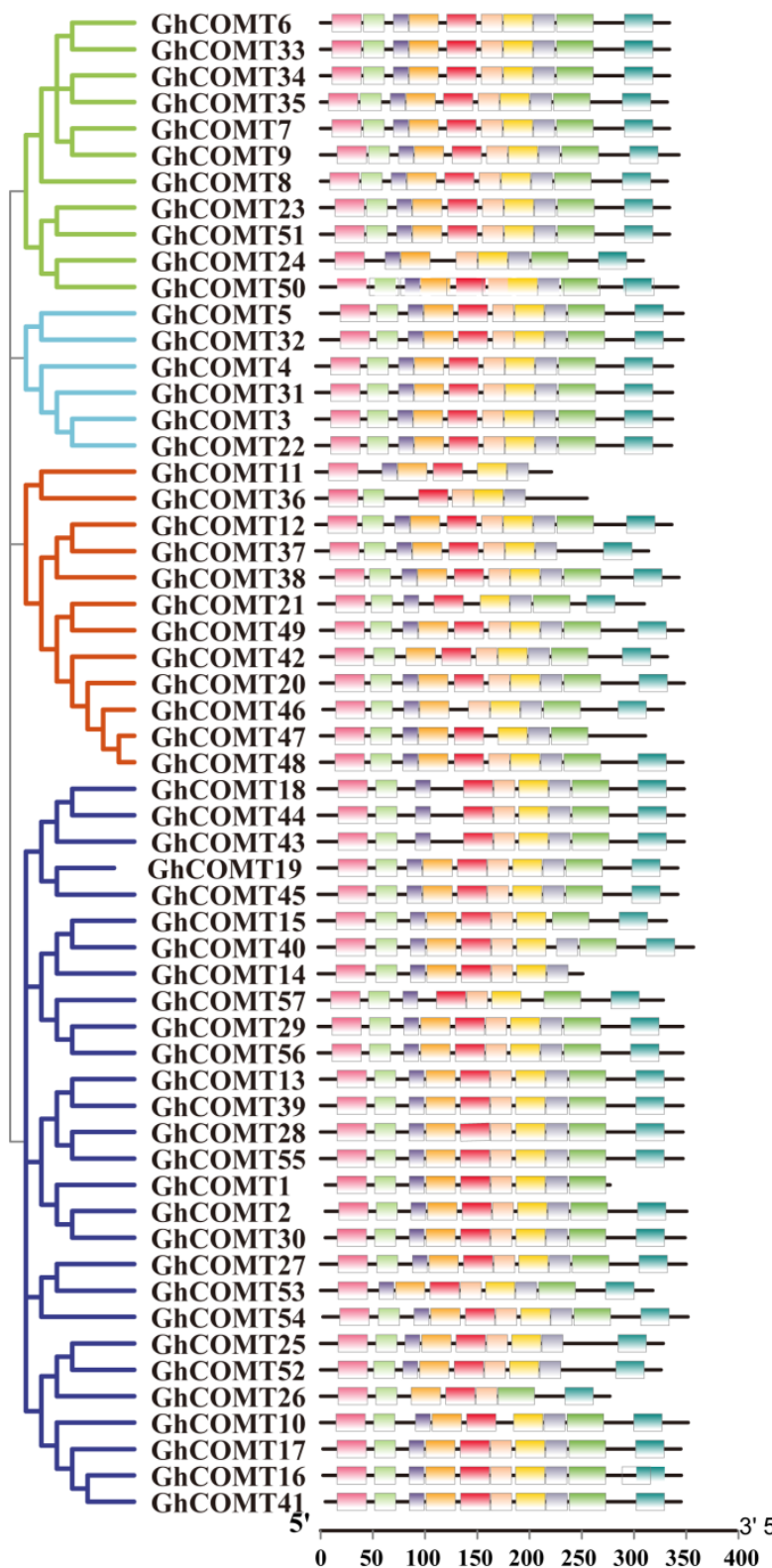

C

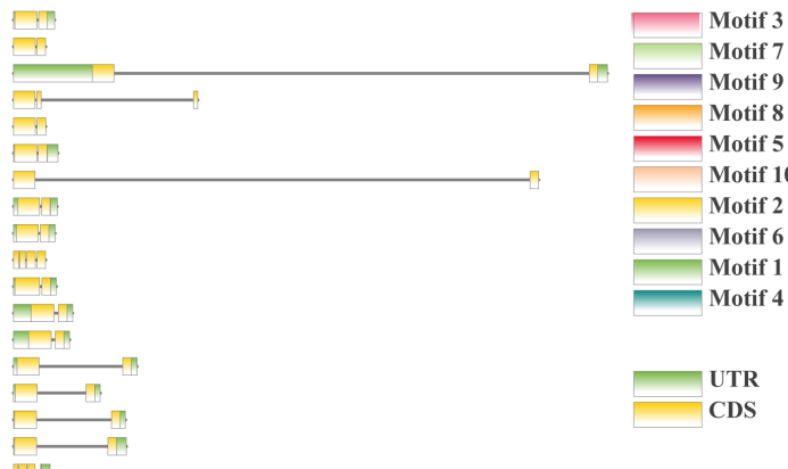

Figure 3. Phylogenetic relationship, conversed protein motif analysis and gene structure predictions of GhCOMT family: (a) a neighbor-joining phylogenetic tree. (b) Conversed protein motifs of the amino acid sequences of GhCOMTs. (c) Gene structure analysis of GhCOMT genes.

According to the conserved protein motifs, all members contained motif 2, 3, 5 and 6 . With the exception of three members having 6-7 motifs, others all contained 8-10 motifs; thus, the GhCOMT gene family was proved to be highly conserved.

\subsection{Collinearity Analysis of the COMT Gene Family in G. arborum, G. hirsutum and G. raimondii}

Gene families are forced through tandem and fragmental DNA duplication $[46,47]$ in the whole genome evolution. We used MCScanX [36] to identify homologous gene pairs, and the result was showed in Figure 4. A total of 37 pairs of COMT genes showed collinear relationship between upland cotton and G. arboretum, and 32 pairs of collinear COMT genes were found between upland cotton and G. raimondii (Table S4). It can be seen from Figure 4 that a total of 16 GrCOMT genes had evolved into two GhCOMT genes. GhCOMT4 and GhCOMT31 were both derived from GrCOMT12, while GhCOMT4 and GhCOMT31 
were genes on $\mathrm{At} 03$ and $\mathrm{Dt} 02$, respectively, indicating that there was a corresponding relationship between At03 and Dt02. It can also be seen from the Table S3 that 30 genes of GhCOMT were derived from 18 genes of GrCOMT, which showed a collinear relationship. Among them, GhCOMT13, GhCOMT28 and GhCOMT55 came from GrCOMT5. Similarly, GhCOMT27, GhCOMT53 and GhCOMT54 came from GrCOMT18; GhCOMT28, GhCOMT39 and GhCOMT54 came from GrCOMT20. It showed that one gene of G. raimondii could be evolved into one gene, two genes and three genes, while one gene of upland cotton may also be evolved from two genes. From the collinear distribution of COMT genes, it can be observed that one gene corresponds to multiple genes, indicating that tandem repeat events occur in the family during evolution, and this phenomenon is more common in subgroup D [21].

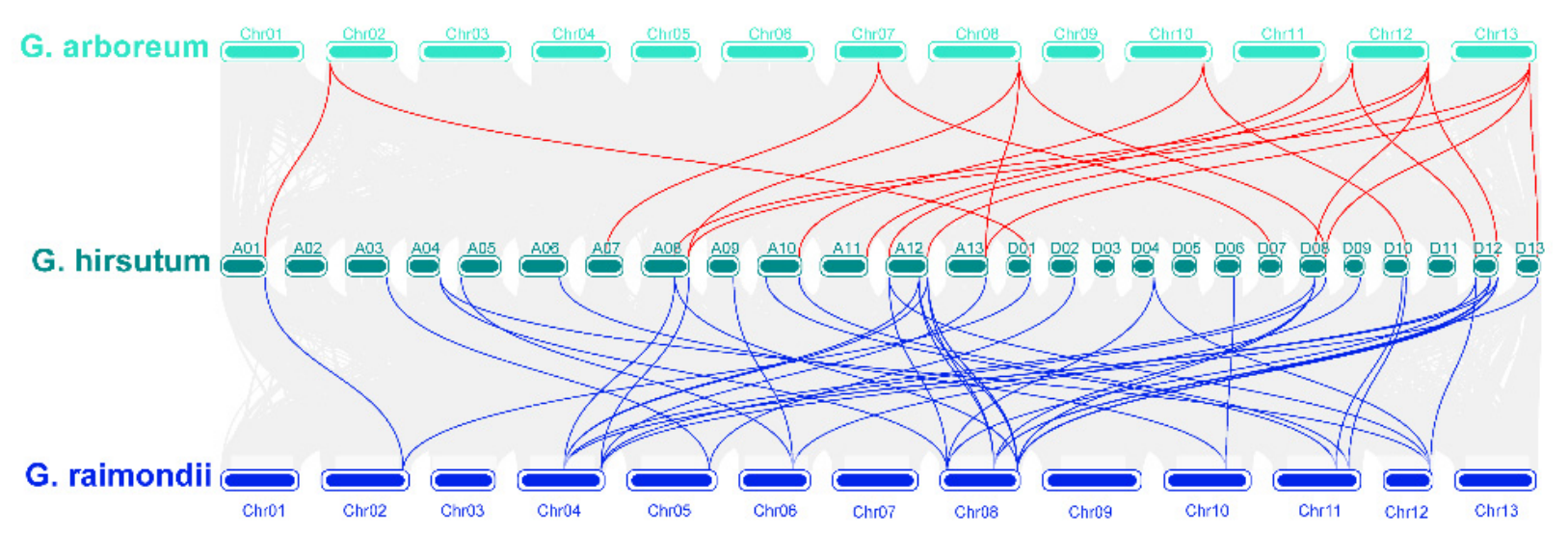

Figure 4. Collinearity of COMT genes between G. hirsutum, G. arboretum and G. raimondii. The synteny of COMTs between G. hirsutum and G. arboreum labeled with red lines and the synteny of COMTs between G. hirsutum and G. raimondii labeled with blue lines.

According to previous studies, a chromosomal region $150-200 \mathrm{~kb}$ in length that contained two or more genes was the evidence of a tandem duplication [48]. A total of 25 gene-pairs with segmental duplication were discovered in G. hirsutum (Figure 3 and Table S5). Moreover, we identified 16, 6 and 14 tandem duplicated gene-pairs in G. hirsutum, G. arboretum and G. raimondii, respectively (Figure 3 and Table S5). Thirty-seven and thirty-two pairs of WGD have been detected between G. hirsutum and G. arboretum and G. hirsutum and G. raimondii (Table S5). All results indicated that both segmental and tandem duplication played essential roles in the expansion of COMT family proteins, while WGDs were predominantly a duplication type between tetraploid and diploid. It can be observed that most of the tandem repeat genes occur in Dt, which is consistent with the results from 2015 where $\mathrm{Li}$ et al. found that $\mathrm{Dt}$ has a higher rate of single base mutation and non-synonymous mutation than At through sequencing cotton genome [21].

From the results of collinearity and $\mathrm{Ka} / \mathrm{Ks}$, we can observe that the COMT genes of G. arboretum and G. raimondii evolved into the COMT genes of subgroup At and subgroup Dt of upland cotton. Some genes of G. arboretum and G. raimondii would also be lost during long-term evolution. In this study, 16 COMT genes were deleted in G. arboretum, and 17 COMT genes were lost in G. raimondii (Table S4).

\subsection{Analysis of Selection Pressure of COMT Genes in Cotton}

The Ka/Ks ratio was calculated to assess selection pressure (Table S4). The ratio of $\mathrm{Ka} / \mathrm{Ks}>1$ indicates that the gene is positively selected; thus, the non-synonymous rates are larger than the synonymous rates [46], when the ratio of $\mathrm{Ka} / \mathrm{Ks}<1$ represents that the gene is selected negatively [46].

We analyzed $\mathrm{Ka} / \mathrm{Ks}$ between $\mathrm{G}$. arboretum and upland cotton and G. raimondii and upland cotton. Between G. arboretum and upland cotton, 37 pairs of G. arboretum and upland cotton had Ka/Ks values, among which the Ka/Ks value of GrCOMT27 and GhCOMT43 was 1.27 , indicating that they evolved through positive selection. There were 11 pairs of 
upland cotton and G. arboretum with $\mathrm{Ka} / \mathrm{Ks}$ values between 0.5 and 1, and 25 pairs had less than 0.5 . Between G. raimondii and upland cotton, the rate of $\mathrm{Ka} / \mathrm{Ks}$ between GrCOMT14 and GhCOMT41 was 1.02, indicating that GhCOMT41 resulted from positive selection. There were seven gene pairs with $\mathrm{Ka} / \mathrm{Ks}$ value between 0.5 and 1 .

\subsection{Expression Patterns of GhCOMT Genes in Fiber Development}

Gene expression patterns are usually related to their functions. A transcriptome analysis of the GhCOMTs was performed using RNA-seq data for different stages of cotton ovule and fiber development (Table S1). The COMT of upland cotton can be clustered into A, B, C and D groups according to their expression in different fiber development stages (Figure 5). In group A, genes were highly expressed in the early stage of fiber development (from -3 DPA to 1 DPA). Group B played a role in the period of secondary wall thickening (10 DPA-30 DPA), and it was the period of lignin synthesis. In group C, COMT plays a role in 3 DPA-7 DPA. In group D, there were 14 COMTs that did not express at any stage of fiber development.

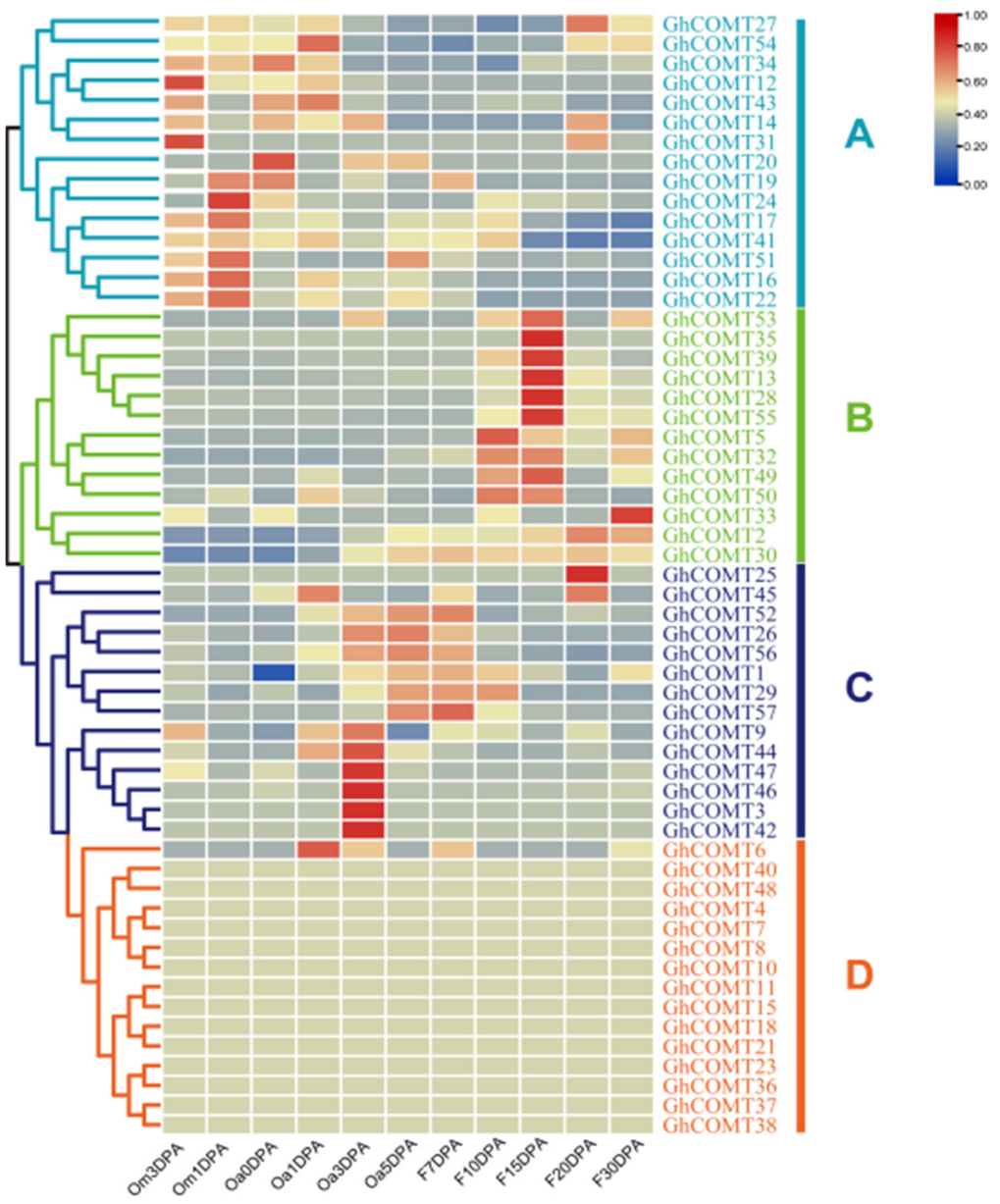

Figure 5. Expression profiles of GhCOMT genes in different fiber development stages. The phylogenetic relationships were displayed on the left, and the gene names were shown on the right; the fiber development stages were shown on the bottom. Scale bars at the right represented $\log 2(\mathrm{FPKM}+1)$. Different colours represent the different expression levels of GhCOMTs. Om3DPA: Ovule at minus 3 day post anthesis; Om1DPA: Ovule at minus 1 day post anthesis; Oa0DPA: Ovule at 0 day post anthesis; Oa1DPA: Ovule at 1 day post anthesis; Oa3DPA: Ovule at 3 day post anthesis; Oa5DPA: Ovule at 5 day post anthesis; F7DPA: Fiber at 7 day post anthesis; F10DPA: Fiber at 10 day post anthesis; F15DPA: Fiber at 15 day post anthesis; F20DPA: Fiber at 20 day post anthesis and F30DPA: Fiber at 30 day post anthesis. FRAM: fragments per kilobase of transcript per million reads. 


\subsection{Analysis of GhCOMT Gene Promoters in the Cotton}

We analyzed the cis-acting elements on cotton COMT genes (Figure 6). The results for cotton COMT genes were similar to the blueberry COMTs [49]. According to the function, the cis-acting elements from COMT genes could be divided into four groups. Light response-related motifs constituted most cis-acting elements in cotton COMT genes and were distributed in all groups. These results showed that the COMT genes in cotton might be controlled by light. Many cis-acting elements related to plant growth and development were found in the promoter region, such as circadian, related to circadian regulatory, GCN4 motif related to endosperm development, RY-element related to seedspecific regulation and MSA-like element related to cell cycle regulation. In the motifs related to stress response, P-box was a gibberellin-responsive element that was a motif related to hormone response. MBS was involved in drought, and LTR was involved in low-temperature responsiveness.

MRE and MBS were both MYB binding sites that belonged to transcription factor binding sites. We found that AuxRR-core and TGA-box were cis-acting elements related to auxin responsiveness in the hormone response motifs. TATA-box and GARE-motif were gibberellin-responsive elements. ABRE was related to abscisic acid. Often, the type and order of cis-acting elements are similar, and the sequences have high similarity on the homologous chromosomes and high collinearity, such as GhCOMT6 and GhCOMT33 and GhCOMT23 and GhCOMT51 in group I. GhCOMT34 and GhCOMT35 are tandem repeat genes, and they have the similar sequence; thus, the cis-acting elements are also similar. There were many pairs of the gene that have a higher similar sequence in other groups. Similarity regulatory elements may have similar gene functions. Many GhCOMTs had LTR related to low-temperature responsiveness and GCN4 motif involved in endosperm expression. The unique regulatory elements may underlie the different functions of the genes in different groups. For example, P-box, related to gibberellin responsiveness, was mainly distributed in group I. GT1-motif, involved in light responsiveness, was mainly distributed in group II. In group III, ERE, related to hormone responsiveness, increased compared to other elements, and G-box, involved in light responsiveness, increased in group IV.

\subsection{GhCOMT Genes Expression in Fiber Development}

According to expression in the transcriptome analysis (Figure 7), 14 GhCOMTs were selected for qRT-PCR at different fiber development stages. In Figure 5, GhCOMT16, GhCOMT17 and GhCOMT41 were in Group A, and their expressions were higher in the initial stage and earlier elongation stage of fiber development. On the other hand, GhCOMT26, GhCOMT56 and GhCOMT57 were in Group C, and their expressions were higher in the elongation stage of fiber development. In addition, GhCOMT2, GhCOMT5, GhCOMT13, GhCOMT28, GhCOMT30, GhCOMT32, GhCOMT39 and GhCOMT55 were in group B. The expressions of GhCOMT5, GhCOMT28, GhCOMT32, GhCOMT39 and GhCOMT55 were higher in the secondary wall thickening stage, while the expressions of GhCOMT2, GhCOMT13 and GhCOMT30 were as higher in the elongation stage and secondary wall thickening stage.

From the results of qRT-PCR, we can observe that the expression trends of GhCOMT28, GhCOMT39 and GhCOMT55 were same; the expression level was higher in 15-30 DPA and the highest is in 20 DPA. The expression of GhCOMT13 was also highest in 20 DPA, indicating that the precursor of lignin would be synthesized the most at this time. In general, lignin synthesis is related to cellulose, but the specific relationship has not been clearly studied. 


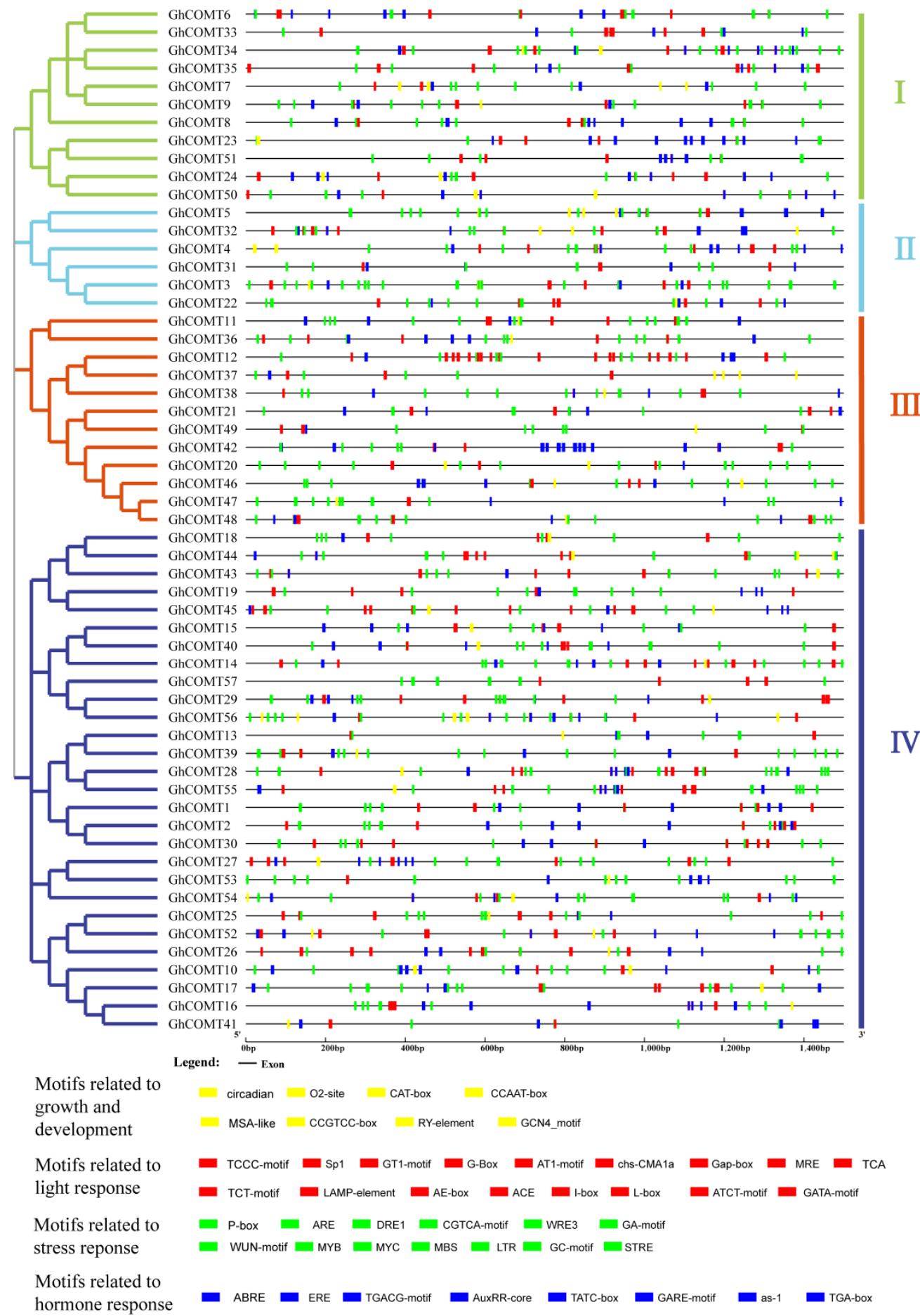

Figure 6. Predicted cis-elements in the promoter regions of GhCOMT genes. GhCOMTs were divided into I, II, III and IV according to the protein sequences. Motif names were showed below with different colors. 


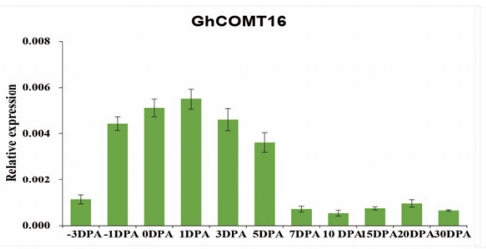

b
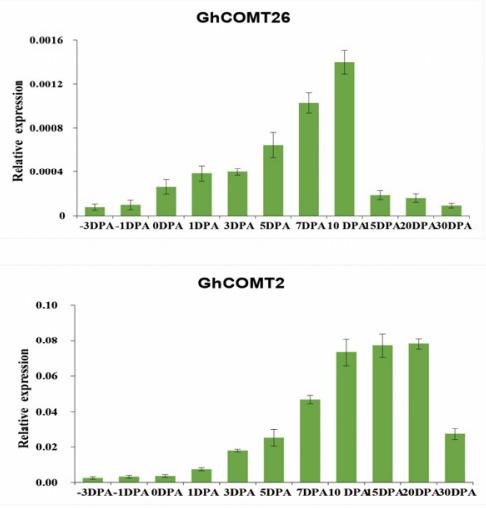

d

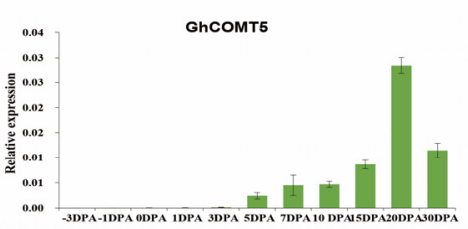

Ghсомтз9

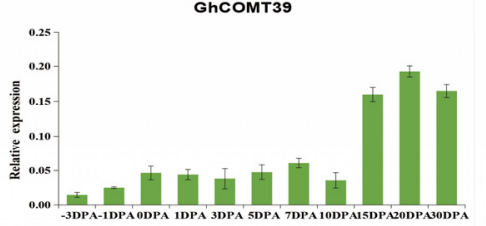

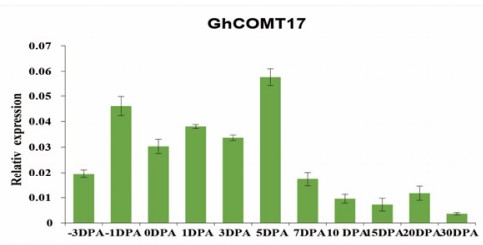

Ghсомт56

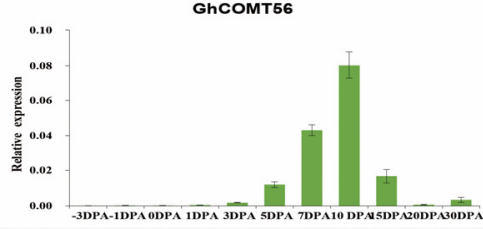

GhCOMT30

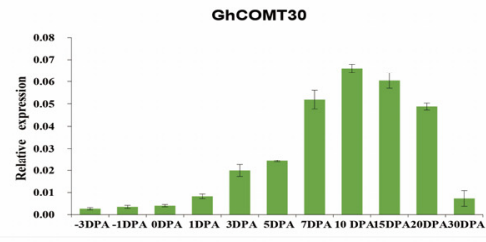

Ghсомт28
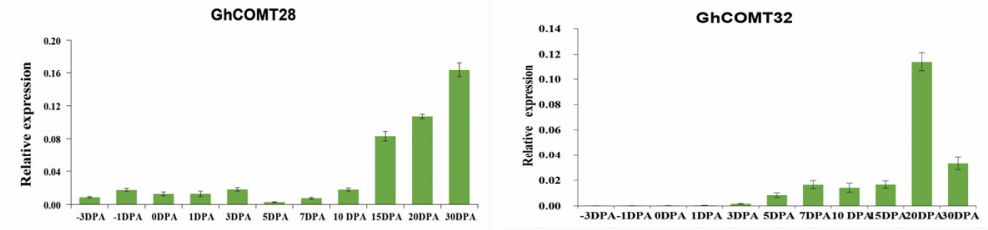

Figure 7. The expression patterns of 14 GhCOMTs at different development stages of cotton fibers by qRT-PCR. (a) Expression profiles of three GhCOMTs highly expressed in the fiber initiation and earlier stages of elongation stage. (b) Expression profiles of three GhCOMTs highly expressed in the fiber elongation stage. (c) Expression profiles of three GhCOMTs highly expressed in the fiber elongation stage and at the secondary wall synthesis stage. (d) Expression profiles of five GhCOMTs highly expressed at the secondary wall synthesis stage. The error bar presents standard deviations of three biological experiments. DPA: day post anthesis. GhHis3 was used as the internal control.

The heat map results showed that the four genes GhCOMT13, GhCOMT28, GhCOMT39 and GhCOM55 were clustered into one group, and their expression was highest in 15DPA (Figure 7). The relative contents of GhCOMT13, GhCOMT28, GhCOMT39 and GhCOMT55 are relatively high during fiber development. From the results of qRT-PCR, we can observe that the expression trend of GhCOMT28, GhCOMT39 and GhCOMT55 was the same; the expression level was higher in 15-30 DPA and the highest in 20DPA.

According to the results of multiple sequences alignment (Figure 8), GhCOMT13, GhCOMT28, GhCOMT39 and GhCOM55 contained the same substrate binding sites with COMT that could contain catalytic caffeic acid and 5-OH coniferaldehyde [50]. 


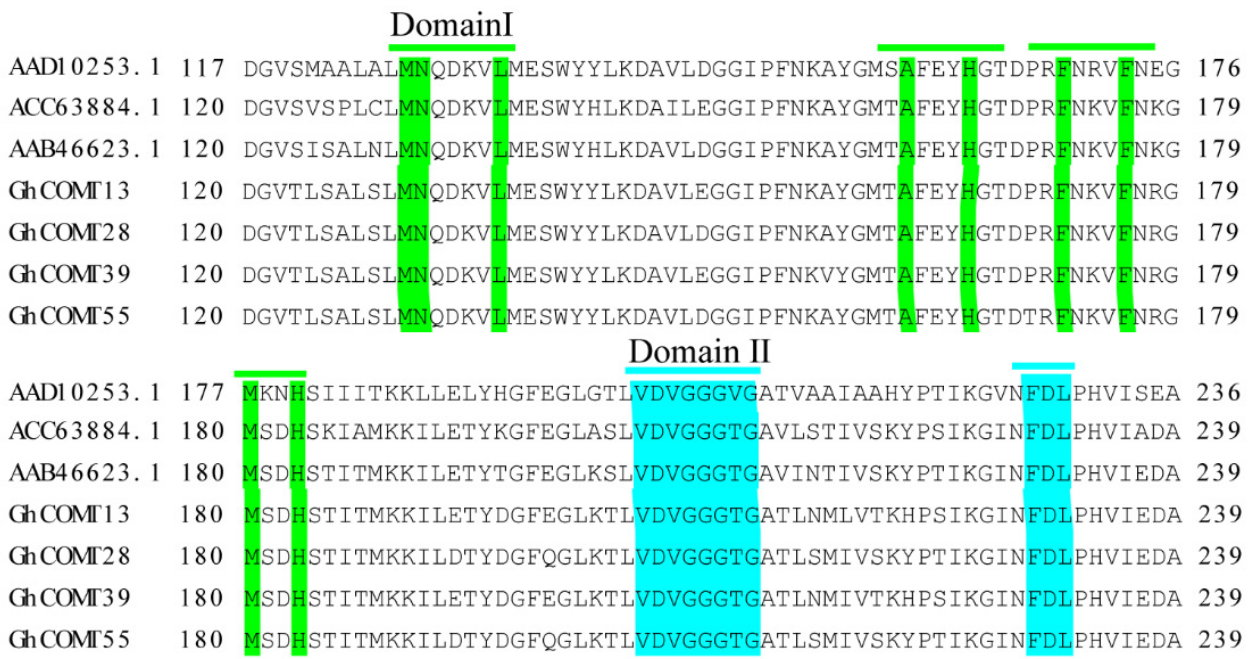

Domain III

AAD1 0253. 1237 PQEPGVTHVGGDMFKEVPSGTILMKWILHDWDSQHCATLLKNCYDALPAHGKVVLVQCI 296 ACC63884. 1240 PAFPGVENVGGDMFVSVPKADAVFMKWICHDWSDEHCLRFLKNCYDALPENGKVILVECI 299 AAB46623. 1240 PSYPGVEHVGGDMFVSIPKADAVFMKWICHDWSDEHCLKFLKNCYEALPDNGKVIVAECI 299 GhCOMI13 240 PAYPGVEHVGGDMFESVPKGDAIFMKWICHDWSDEHCSKFLKKCYEALPDNGKVIVAECI 299 GhCOMI28 240 PSCPGVEHVGGDMFVSVPKGDAIFMKWICHDWSDEHCAKFLKNCYEALPDNGKVIVAECI 299 GhCOMI39 240 PAYPGVEHVGGDMFESVPKGDAIFMKWICHDWSDEHCSKFLKKCYEALPDSGKVIVAECI 299 GhCOMT55 240 PSCPGVEHVGGDMFVSVPKGDAIFMKWICHDWSDEHCAKELKNCYEALPDNGKVIVAECI 299

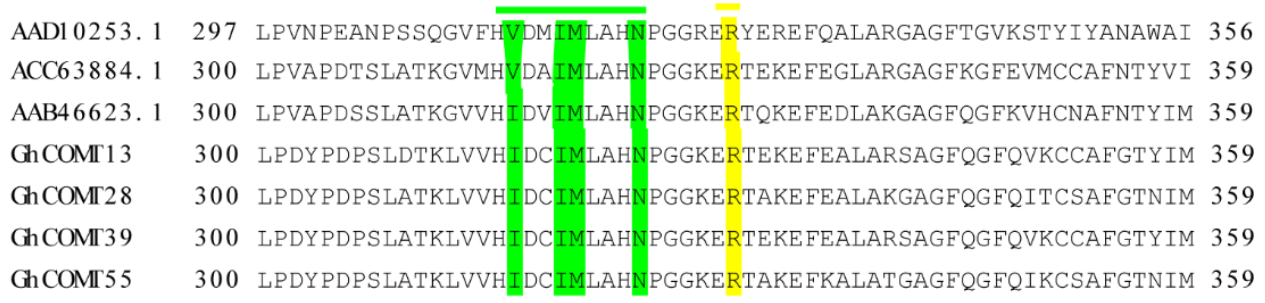

Figure 8. GhCOMT13, GhCOMT28, GhCOMT39 and GhCOM55 multiple sequence alignment was performed with other related to lignin COMT. Domain I (Green): substrate binding site; Domain II (Blue): SAM binding site; Domain III (Yellow): catalytic residues.

\subsection{Response of GhCOMTs in VW}

$V$. dahliae was inoculated into TM-1. In the diseased plants and controls, we extracted RNA from roots, stems, cotyledons and true leaves and detected the expression of GhCOMT genes in these organs. The values are standardized. The results (Figure 9) showed that the expression of GhCOMT5 and GhCOMT32 in roots and stems of diseased plants was higher than $\mathrm{CK}$, and the expression of GhCOMT5 in roots of diseased plants was significantly higher than CK. The expressions of GhCOMT28, GhCOMT39 and GhCOMT57 in cotyledons of diseased plants were significantly higher than CK. The expressions of GhCOMT26, GhCOMT56 and GhCOMT57 in cotyledons, stems and true leaves of diseased plants were higher than CK. Among them, the expressions of GhCOMT56 and GhCOMT57 in cotyledons and stems of diseased plants were significantly higher than CK. 
a
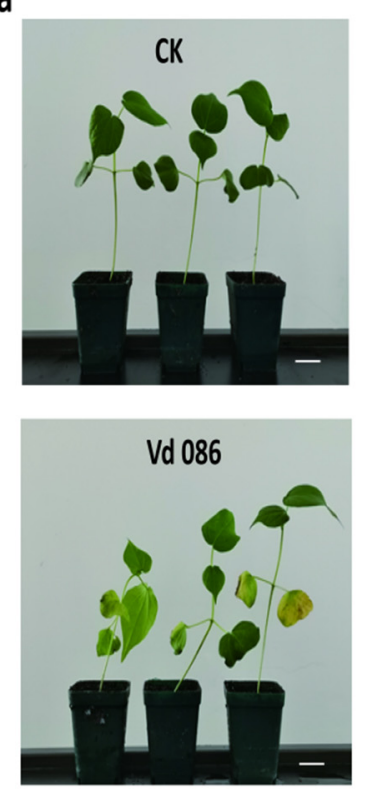

b
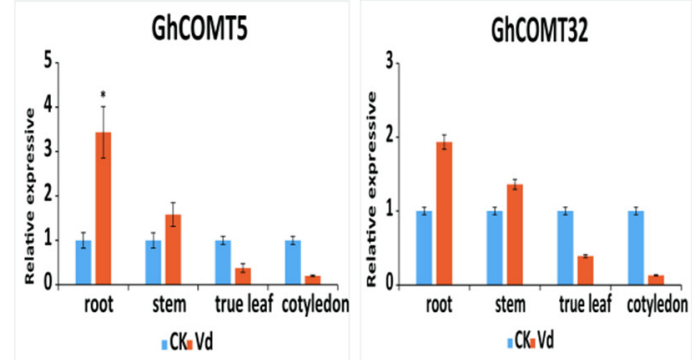

C
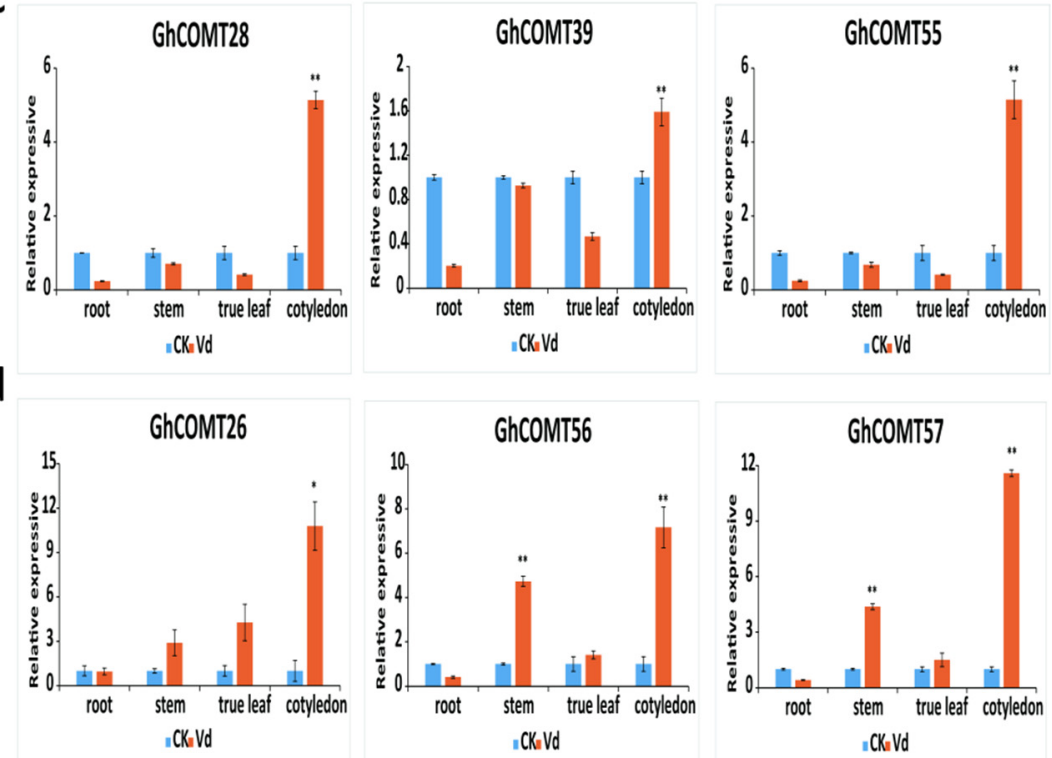

Figure 9. (a) Disease symptoms of cotton plants after 7 days inoculation with $V$. dahliae strain Vd086. Bar $=1 \mathrm{~cm}$. (b-d) shows that the expression patterns of 8 GhCOMTs at different organs with $V$. dahliae and CK(mock). The values are standardized. GhUBQ7 (DQ116441) was used as the internal control. Each experiment was performed in three biological replicates, and the error bars represent mean $\pm \mathrm{SD} ; n=3 .{ }^{*} p<0.05 ;{ }^{* *} p<0.01$.

\section{Discussion}

Lignin is the basic framework of cellulose; thus, it plays an important role in woody plants, such as transporting water and enhancing resistance, etc. Lignin also plays a vital role in gramineous crops. For example, overexpression of COMT in Arabidopsis thaliana can promote melatonin synthesis and improve drought resistance [15]. The overexpression of TaCOMT-3D increased the resistance of transgenic wheat to sheath blight, stem mechanical strength and the accumulation of lignin in transgenic wheat [51]. In sorghum bmr mutants, the loss of COMT activity reduced lateral root formation and changed water restriction [20]. In addition, there are many more studies on COMT in other plants, such as tobacco [52], oatgrass [53], pine [54], rice [18], barley [19] and blueberry fruit [49]. In cotton, N-acetyltransferase 1 (GhSNAT1) and caffeic acid O-methyltransferase (GhCOMT) silencing results in a decrease in melatonin biosynthesis, which affects lignin and gossypol synthesis. It reduces resistance to $V$. dahlia [55].

Our study identified 57 GhCOMT genes in the cotton $(\mathrm{AD})_{1}$ genomes, $60 \mathrm{GbCOMT}$ genes in (AD) 2 genomes, 38 GaCOMT genes in At genomes and 35 GrCOMT genes in Dt genomes. These results suggested that GhCOMT genes were lost in allotetraploid G. hirsutum, which was consistent with the higher rate of gene loss in allotetraploids [21,22]. According to the protein domain, 190 genes of four cotton species were divided into three groups. Group I and group II contained three subgroups, while group III had four subgroups. It can also be observed that Arabidopsis was herbaceous, while cotton was woody and the lignin synthesis in Arabidopsis thaliana and cotton should be different; thus, 
the distribution of COMT was also quite different. For further identifying the conservation of upland cotton, gene motifs of GhCOMTs were analyzed. Most of the genes had ten motifs, but some genes had less than ten motifs, which had different regulatory mechanisms (Figure 3). In the same family, the exons, introns and motifs had similar arrangements, which further proved the COMT classifications' correctness. We identified these motifs, which were highly conserved in GhCOMTs. Some residues in three domains (Figure 8) (domain I: MN, L, A, H, F, F, M, H; domain II: VDVGGTG, FDL, DMF, K, W; and domain III: H, E, M, N) are related to the SAM/SAH binding site [56]. Domain I was distributed in motif 4, 5, 8 and 10 (Figure S1). Motif 2 and motif 6 of the GhCOMTs contained domain II (Figure S1). Domain III was dispersed in motif 1 and 4 (Figure S1).

Collinearity and $\mathrm{Ka} / \mathrm{Ks}$ are more likely to prove tandem repetitive events. $\mathrm{Ka} / \mathrm{KsThe}$ $\mathrm{Ka} / \mathrm{Ks}$ of GrCOMT27/GhCOMT43 was 1.27, indicating that GhCOMT43 was produced by positive selection. By examining the $\mathrm{Ka} / \mathrm{Ks}$ results (Table $\mathrm{S} 4$ ), it can also be seen that 21 GaCOMTsevolved into 34 GhCOMTs, and 18 GrCOMTs evolved into 30 GhCOMTs. With respect to $\mathrm{Ka} / \mathrm{Ks}$ between G. hirsutum and G. raimondii, it was found that only GhCOMT41 came from GrCOMT14 with a Ka/Ks value of 1.01, which was the result of positive selection. The Ka/Ks value of other genes was less than 1, which were resulted from adverse selection [48]. There were two pairs of $\mathrm{Ka} / \mathrm{Ks}$ values greater than one between the two diploids and upland cotton, while the $\mathrm{Ka} / \mathrm{Ks}$ value of other genes was less than 0.6, indicating that the selection pressure was slight.

Go analysis showed that 50 GhCOMT genes were involved in molecular function, and there were three enrichment GO items. The molecular function includes the following aspects: (1) O-methyltransferase activity, 49 genes (98.00\%); (2) methyltransferase activity, 49 genes (98.00\%); and (3) protein dimerization activity, 47 genes (94.00\%) (Figure S2 and Table S6). O-methyltransferase and methyltransferase activity play key roles in converting phenylalanine into lignin $[9,10]$.

Cotton functional genomics database (https: / / cottonfgd.org, accessed on 10 July 2021) was used to analyze methyltransferase activity of G. hirsutum to determine the function and metabolic process of GhCOMTs. KEGG analysis showed that there were five enrichment KEGG pathway items. There are 25 genes matched KEGG pathway items: monolignol biosynthesis, 22 genes ( $88.00 \%)$; phenylpropanoid biosynthesis, 22 genes $(88.00 \%)$; biosynthesis of secondary metabolites, 22 genes $(88.00 \%)$; metabolic pathways, 22 genes $(88.00 \%)$; and stilbenoid, diarylheptanoid and gingerol biosynthesis, 3 genes $(12.00 \%)$. For a better display, we transformed the q value into an integer ( $-\log 2(\mathrm{q})$ ) (Figure S3 and Table S6). Our further analysis found that 22 genes that matched monolignol biosynthesis (phenylalanine/tyrosine), phenylpropanoid biosynthesis and biosynthesis of secondary metabolites and metabolic pathways belonged to group IV, which encodes COMTs. Three genes that matched stilbenoid, diarylheptanoid and gingerol biosynthesis belonged to group III, which encodes ROMTs (Trans-resveratrol di-O-methyltransferase). Monolignol biosynthesis consists three reference pathways: Phenylpropanoids are a group of plant secondary metabolites derived from phenylalanine. After deaminization, hydroxylation, methylation and CoA-activated, phenylalanine was converted to corresponding aldehydes and alcohols. These alcohols are called monolignols, which are the starting compounds for lignin biosynthesis. In Arabidopsis, AtCOMT is an important enzyme in lignin synthesis [11,12].

The expression profiling in eleven different fiber development periods showed that GhCOMT13, GhCOMT28, GhCOMT39 and GhCOMT55 had higher expression in 15DPA and may potentially function in fiber development (Figure 7). The qRT-PCR results of ovule development in $-3,-1,0,1,3,5,7,10,15,20$ and 30DPA showed that GhCOMT13, GhCOMT28, GhCOMT39 and GhCOMT55 were highly expressed at 20DPA, especially GhCOMT28. GhCOMT13 and GhCOMT39 were expressed during -3DPA to 10DPA, but GhCOMT28 and GhCOMT55 had lower expressions than GhCOMT13 and GhCOMT39. These results showed that COMT genes had different expressions in different development periods but were highly expressed at secondary cell wall synthesis (16-21DPA). Furthermore, 18-21 DPA was critical for cell wall remodeling and synthesis of winding 
layer $[57,58]$. During fiber development, lignin content in fiber was shallow and gradually increased in the secondary wall thickening stage. The fiber mainly consisted of the ovule in the early stage, which had nearly no lignin content. The fiber cell was becoming thin and long during the rapid cell growth stage, and cellulose content gradually increased. From the secondary wall thickening stage, the fiber in the boll swells and hardens, and the water content showed a downward trend. Based on the GhCOMT fiber differential expression data from RNA-seq (Figure 7), 14 GhCOMTs were selected to detect gene expression using qRT-PCR. Previous studies have shown that lignin or lignin-like phenolics exist in cotton fibers $[59,60]$ and contribute to the changes in the SCW and fiber strength of the transgenic lines [61,62]. The expression of COMT gene (GhCOMT13, GhCOMT28, GhCOMT39 and GhCOMT55) in the periplasmic space increased and resulted in lignin accumulated in the fiber cells, which was shown by the cell wall gradually thickening [30]. Previous studies revealed that the OMT gene family was a strong growth regulator and was involved in fiber elongation and secondary cell wall synthesis stages [29]. There were three differences between this paper and Abdul et al. First of all, the reference genomes of G. hirsutum were different. This study used HAU genome data, and NAU genome data was analysed in Abdul's article. Secondly, transcriptome data were different. The expessions of OMT genes were detected by using transcriptome of Chromosome Substitution Segment Lines (CSSLs) and Recombination Inbred Lines (RILs) in the previous research [29]. In this study, the heatmap of upland cotton was made by the transcriptome of standard genetic cotton cultivar TM-1, and the expression of COMT genes was detected by the cDNA of different stages of fiber development by qRT-PCR. Third, another main content was to study the relationship between COMT and VWresistance in this article, while Abdul et al. [29] studied the relationship between OMT and salt stress. The similarity between the two articles was that the sequence of GhOMT49_At, GhOMT49_Dt and GhOMT48_At [29] was the same as GhCOMT13 and GhCOMT39 and GhCOMT28 in our study, indicating that these three genes did play an important role in fiber development. The thickening of the cell wall of cotton fiber also resulted in an increase in micronaire value $[59,60]$. Generally, the micronaire value of cotton was rated as Grade A in the range of 3.7-4.2, and the spinning quality was the best. Therefore, COMT gene had an essential effect on cotton fiber quality.

VW was absorbed from the root and transmitted to cotyledons and true leaves through the stem. The results of inoculation experiment of VWshowed that 6GhCOMTs responded in cotyledons, and the expression of GhCOMT28, GhCOMT39, GhCOMT55, GhCOMT56 and GhCOMT57 in cotyledons reached a very significant difference. The expression of GhCOMT26, GhCOMT28, GhCOMT55, GhCOMT56 and GhCOMT57 was almost5 times than CK, indicating that these genes responded to VW. Previous studies showed that OMT genes were induced by inoculation of $V$. dahliae and the expression patterns of phenylpropanoid changed during the inoculation of pathogens $[31,63,64]$. In the process of fiber development, the expression of GhCOMT13, GhCOMT28, GhCOMT39 and GhCOMT55 increased; thus, lignin synthesis was also increasing. At the same time, cotton plants might be infected by VW. GhCOMT28, GhCOMT39, GhCOMT55, GhCOMT56 and GhCOMT57 would respond to synthesize lignin and inhibit the expansion of VW. It had been reported that silencing caffeic acid O-methyltransferase (GhCOMT) melatonin biosynthesis genes weakened cotton resistance to VW with reduced lignin [55].

\section{Conclusions}

In this study, the COMT family in the whole genome of cotton was identified, and its gene structure, conservative structure, evolutionary relationship and collinear analysis were deeply analyzed. The results provide an essential reference value to further study the evolution and specific function of the GhCOMT gene family. Secondly, given the vital role of GhCOMT genes in the secondary wall thickening stage of G. hirsutum fiber development, we can speculate that GhCOMTs affect fiber strength and micronaire value and have important values for improving fiber quality and resistance to VW. Thirdly, in response to VW, it is speculated that GhCOMTs may play a role in VW resistance. 
Supplementary Materials: The following are available online at https: / www.mdpi.com/article/ $10.3390 /$ plants10122756/s1, Figure S1. The motif of GhCOMT with domains. Figure S2. The result of GO analysis. Figure S3. The result of KEGG analysis. Table S1. Primer sequences of GhCOMT genes. Table S2. Correspondence of gene name and gene ID in cotton and Arabidopsis thaliana. Table S3. The Ka and Ks values for homologous pairs; missing genes of G. arboretum and G. raimondii. Table S4. The FPKM value of all genes in G. hirsutum L.cultivar Texas Marker-1 (TM-1) during fiber development. Table S5. Genes matched GO analysis. Table S6. Genes matched KEGG pathway items.

Author Contributions: G.S. and C.W. managed the project and designed the research. C.W., D.Z., S.X., Q.W., H.C., L.L. and Y.Z. performed the experiments and prepared figures and tables. C.W., D.Z., S.X. and P.L. wrote and revised the paper. All authors have read and agreed to the published version of the manuscript.

Funding: This research is financially supported by the National Key R and D Plan of China (No. 2018YFD0100402), National Natural Science Foundation of China (No. 31621005 and No. 31901581), Central Public-interest Scientific Institution Basal Research Fund (No.1610162021013) and Agricultural Science and Technology Innovation Program of Chinese Academy of Agricultural Sciences. The funders had no role in the design of the study, collection, analysis or interpretation of the data; the writing of the manuscript; or the decision to submit the manuscript for publication.

Institutional Review Board Statement: Not applicable.

Informed Consent Statement: Not applicable.

Data Availability Statement: The data presented in this study are available in the article and Supplementary Materials.

Conflicts of Interest: The authors declare that they have no conflict of interest.

\section{References}

1. Applequist, W.L.; Cronn, R.; Wendel, J.F. Comparative development of fiber in wild and cultivated cotton. Evol. Dev. 2001, 3, 3-17. [CrossRef]

2. Arpat, A.B.; Waugh, M.; Sullivan, J.P.; Gonzales, M.; Frisch, D.; Main, D.; Wood, T.; Leslie, A.; Wing, R.A.; Wilkins, T.A. Functional genomics of cell elongation in developing cotton fibers. Plant Mol. Biol. 2004, 54, 911-929. [CrossRef] [PubMed]

3. Kim, H.J.; Triplett, B.A. Cotton fiber growth in planta and in vitro. Models for plant cell elongation and cell wall biogenesis. Plant Physiol. 2001, 127, 1361-1366. [CrossRef]

4. Haigler, C.H.; Betancur, L.; Stiff, M.R.; Tuttle, J.R. Cotton fiber: A powerful single-cell model for cell wall and cellulose research. Front. Plant Sci. 2012, 3, 104. [CrossRef]

5. Mansoor, S.; Paterson, A.H. Genomes for jeans: Cotton genomics for engineering superior fiber. Trends Biotechnol. 2012, 30, 521-527. [CrossRef] [PubMed]

6. Vanholme, R.; De Meester, B.; Ralph, J.; Boerjan, W. Lignin biosynthesis and its integration into metabolism. Curr. Opin. Biotechnol. 2019, 56, 230-239. [CrossRef]

7. Lewis, N.G.; Yamamoto, E. Lignin: Occurrence, biogenesis and biodegradation. Annu. Rev. Plant Physiol. Plant Mol. Biol. 1990, 41, 455-496. [CrossRef] [PubMed]

8. Wilson, J.R.; Mertens, D.R. Cell wall accessibility and cell structure limitations to microbial digestion of forage. Crop Sci. 1995, 35, 251-259. [CrossRef]

9. Guo, A.Y.; Zhu, Q.H.; Chen, X.; Luo, J.C. GSDS: A gene structure display server. Hereditas 2007, 29, 1023-1026. [CrossRef] [PubMed]

10. Bugos, R.C.; Chiang, V.; Campbell, W.H. cDNA cloning, sequence analysis and seasonal expression of lignin-bispecific caffeic acid/5-hydroxyferulic acid O-methyltransferase of aspen. Plant Mol. Biol. 1991, 17, 1203-1215. [CrossRef] [PubMed]

11. Lee, H.Y.; Byeon, Y.; Lee, K.; Lee, H.; Back, K. Cloning of Arabidopsis serotonin N-acetyltransferase and its role with caffeic acid O-methyltransferase in the biosynthesis of melatonin in vitro despite their different subcellular localizations. J. Pineal. Res. 2015, 57, 418-426. [CrossRef] [PubMed]

12. Lam, K.C.; Ibrahim, R.K.; Behdad, B.; Dayanandan, S. Structure, function, and evolution of plant O-methyltransferases. Genome 2007, 50, 1001-1013. [CrossRef] [PubMed]

13. Thomas, G.; Sibout, R.; Pollet, B.; Maba, B.; Nussaume, L. A new Arabidopsis thaliana mutant deficient in the expression of O-methyltransferase impacts lignins and sinapoyl esters. Plant Mol. Biol. 2003, 51, 973-989.

14. Byeon, Y.; Lee, H.Y.; Lee, K.; Back, K. Caffeic acid O-methyltransferase is involved in the synthesis of melatonin by methylating N-acetylserotonin in Arabidopsis. J. Pineal. Res. 2015, 57, 219-227. [CrossRef] [PubMed]

15. Yang, W.J.; Du, Y.T.; Zhou, Y.B.; Chen, J.; Xu, Z.S.; Ma, Y.Z.; Chen, M.; Min, D.H. Overexpression of TaCOMT improves melatonin production and enhances drought tolerance in transgenic Arabidopsis. Int. J. Mol. Sci. 2019, 20, 652. [CrossRef] 
16. Wang, M.J.; Wang, P.C.; Lin, M.; Ye, Z.X.; Li, G.L.; Tu, L.L.; Shen, C.; Li, J.Y.; Yang, Q.Y.; Zhang, X.L. Evolutionary dynamics of 3D genome architecture following polyploidization in cotton. Nat. Plants 2018, 4, 90-97. [CrossRef]

17. Séverine, H.; Camille, A.; Sébastien, A.; Brigitte, B.; Laurent, C.; Le, B.P.; Frédéric, L.; Alessandra, M.G.; Arata, Y.; Luc, S. Mutation in Brachypodium caffeic acid O-methyltransferase 6 alters stem and grain lignins and improves straw saccharification without deteriorating grain quality. J. Exp. Bot. 2016, 67, 227-237.

18. Choi, G.H.; Lee, H.Y.; Back, K. Chloroplast overexpression of rice caffeic acid O-methyltransferase increases melatonin production in chloroplasts via the 5-methoxytryptamine pathway in transgenic rice plants. J. Pineal Res. 2017, 63, e12412. [CrossRef]

19. Daly, P.; McClellan, C.; Maluk, M.; Oakey, H.; Lapierre, C.; Waugh, R.; Stephens, J.; Marshall, D.; Barakate, A.; Tsuji, Y.; et al. RNAi-suppression of barley caffeic acid O-methyltransferase modifies lignin despite redundancy in the gene family. Plant Biotechnol. J. 2019, 17, 594-607. [CrossRef]

20. Saluja, M.; Zhu, F.Y.; Yu, H.F.; Walia, H.; Sattler, S.E. Loss of COMT activity reduces lateral root formation and alters the response to water limitation in sorghum brown midrib (bmr) 12 mutant. New Phytol. 2021, 229, 2780-2794. [CrossRef] [PubMed]

21. Li, F.G.; Fan, G.Y.; Lu, C.R.; Xiao, G.H.; Zou, C.S.; Kohel, R.J.; Ma, Z.Y.; Shang, H.H.; Ma, X.F.; Wu, J.Y.; et al. Genome sequence of cultivated Upland cotton (Gossypium hirsutum TM-1) provides insights into genome evolution. Nat. Biotechnol. 2015, 33, 524-530. [CrossRef]

22. Zhang, T.Z.; Hu, Y.; Jiang, W.K.; Fang, L.; Guan, X.Y.; Chen, J.D.; Zhang, J.B.; Saski, C.A.; Scheffler, B.E.; Stelly, D.M.; et al. Sequencing of allotetraploid cotton (Gossypium hirsutum L. acc. TM-1) provides a resource for fiber improvement. Nat. Biotechnol. 2015, 33, 531-537. [CrossRef]

23. Wang, M.X.; Zhu, X.L.; Wang, K.; Lu, C.G.; Luo, M.Y.; Shan, T.L.; Zhang, Z.Y. A wheat caffeic acid 3-O-methyltransferase TaCOMT-3D positively contributes to both resistance to sharp eyespot disease and stem mechanical strength. Sci. Rep. 2018, 8, 6543. [CrossRef] [PubMed]

24. Hu, Y.; Chen, J.D.; Fang, L.; Zhang, Z.Y.; Ma, W.; Niu, Y.C.; Ju, L.Z.; Deng, J.Q.; Zhao, T.; Lian, J.M.; et al. Gossypium barbadense and Gossypium hirsutum genomes provide insights into the origin and evolution of allotetraploid cotton. Nat. Genet. 2019, 51, 739-748. [CrossRef]

25. Liu, X.; Zhao, B.; Zheng, H.J.; Hu, Y.; Lu, G.; Yang, C.Q.; Chen, J.D.; Chen, J.J.; Chen, D.Y.; Zhang, L.; et al. Gossypium barbadense genome sequence provides insight into the evolution of extra-long staple fiber and specialized metabolites. Sci. Rep. 2015, 5, 14139. [CrossRef] [PubMed]

26. Paterson, A.H.; Wendel, J.F.; Gundlach, H.; Guo, H.; Jenkins, J.; Jin, D.; Llewellyn, D.; Showmaker, K.C.; Shu, S.; Udall, J.; et al. Repeated polyploidization of Gossypium genomes and the evolution of spinnable cotton fibres. Nature 2012, 492, $423-427$. [CrossRef] [PubMed]

27. Wang, K.B.; Wang, Z.W.; Li, F.G.; Ye, W.W.; Wang, J.Y.; Song, G.L.; Yue, Z.; Cong, L.; Shang, H.H.; Zhu, S.L.; et al. The draft genome of a diploid cotton Gossypium raimondii. Nat. Genet. 2012, 44, 1098-1103. [CrossRef] [PubMed]

28. Li, F.G.; Fan, G.Y.; Wang, K.B.; Sun, F.M.; Yuan, Y.L.; Song, G.L.; Li, Q.; Ma, Z.Y.; Lu, C.R.; Zou, C.S.; et al. Genome sequence of the cultivated cotton Gossypium arboreum. Nat. Genet. 2014, 46, 567-572. [CrossRef] [PubMed]

29. Hafeez, A.; Gě, Q.; Zhāng, Q.; Lǐ, J.; Gōng, J.; Liú, R.; Shí, Y.; Shāng, H.; Liú, À.; Iqbal, M.S.; et al. Multi-responses of O-methyltransferase genes to salt stress and fiber development of Gossypium species. BMC Plant Biol. 2021, 21, 37. [CrossRef]

30. Ni, Z.Y.; Lv, M.; Li, B.; Wang, J.; Bai, Y.; Fan, L. Cloning and Characterization of COMT Genes from Gossypium hirsuturm L. Scientia. Agric. Sinica. 2010, 43, 1117-1126.

31. Grimmig, B.; Kneusel, R.; Junghanns, K.; Matern, U. Expression of BifunctionaI Caffeoyl-CoA 3-O-methyltransferase in stress compensation and lignification. Plant Biol. 1999, 1, 299-310. [CrossRef]

32. Horton, P.; Park, K.J.; Obayashi, T.; Fujita, N.; Harada, H.; Adams-Collier, C.J.; Nakai, K. WoLF PSORT: Protein localization predictor. Nucleic Acids Res. 2007, 35, W585-W587. [CrossRef] [PubMed]

33. Yu, C.S.; Chen, Y.C.; Lu, C.H.; Hwang, J.K. Prediction of protein subcellular localization. Proteins 2006, 64, 643-651. [CrossRef]

34. Thompson, J.; Gibson, T.J.; Higgins, D.G. Multiple sequence alignment using ClustalW and ClustalX. Curr. Protoc. Bioinform. 2002, Chapter 2, 1-22. [CrossRef]

35. Tamura, K.; Stecher, G.; Peterson, D.; Filipski, A.; Kumar, S. MEGA6: Molecular evolutionary genetics analysis version 6.0. Mol. Biol. Evol. 2013, 30, 2725-2729. [CrossRef] [PubMed]

36. Wang, Y.; Tang, H.; Debarry, J.D.; Tan, X.; Li, J.; Wang, X.; Lee, T.H.; Jin, H.; Marler, B.; Guo, H.; et al. MCScanX: A toolkit for detection and evolutionary analysis of gene synteny and collinearity. Nucleic. Acids. Res. 2012, 40, e49. [CrossRef]

37. Chen, C.J.; Chen, H.; Zhang, Y.; Thomas, H.R.; Frank, M.H.; He, Y.H.; Xia, R. TBtools: An integrative toolkit developed for interactive analyses of big biological data. Mol. Plant. 2020, 13, 1194-1202. [CrossRef]

38. Wang, D.P.; Zhang, Y.B.; Zhang, Z.; Zhu, J.; Yu, J. KaKs_Calculator 2.0: A toolkit incorporating gamma-series methods and sliding window strategies. Genom. Proteom. Bioinform. 2010, 8, 77-80. [CrossRef]

39. Hu, B.; Jin, J.P.; Guo, A.Y.; Zhang, H.; Luo, J.C.; Gao, G. GSDS 2.0: An upgraded gene feature visualization server. Bioinformatics 2015, 31, 1296-1297. [CrossRef] [PubMed]

40. Bailey, T.L.; Mikael, B.; Buske, F.A.; Martin, F.; Grant, C.E.; Luca, C.; Ren, J.; Li, W.W.; Noble, W.S. MEME Suite: Tools for motif discovery and searching. Nucleic Acids Res. 2009, 37, W202-W208. [CrossRef] 
41. Heinz, S.; Benner, C.; Spann, N.; Bertolino, E.; Lin, Y.C.; Laslo, P.; Cheng, J.X.; Murre, C.; Singh, H.; Glass, C.K. Simple combinations of lineage-determining transcription factors prime cis-regulatory elements required for macrophage and B cell identities. Mol. Cell. 2010, 38, 576-589. [CrossRef]

42. Wang, K.; Wang, D.; Zheng, X.; Qin, A.; Zhou, J.; Guo, B.; Chen, Y.; Wen, X.; Ye, W.; Zhou, Y.; et al. Multi-strategic RNA-seq analysis reveals a high-resolution transcriptional landscape in cotton. Nat. Commun. 2019, 10, 4714. [CrossRef] [PubMed]

43. Wu, Y.; Machado, A.C.; White, R.G.; Llewellyn, D.J.; Dennis, E.S. Expression profifiling identififies genes expressed early during lint fifibre initiation in cotton. Plant Cell Physiol. 2006, 47, 107-127. [CrossRef]

44. Livak, K.J.; Schmittgen, T.D. Analysis of relative gene expression data using real-time quantitative PCR and the 2(-Delta Delta CT Method. Methods 2001, 25, 402-408. [CrossRef]

45. Xu, F.; Yang, L.; Zhang, J.; Guo, X.; Zhang, X.; Li, G. Prevalence of the defoliating pathotype of Verticillium dahliaeon cotton in central China and virulence on selected cotton cultivars. J. Phytopathol. 2012, 160, 369-376. [CrossRef]

46. Cannon, S.B.; Mitra, A.; Baumgarten, A.; Young, N.D.; May, G. The roles of segmental and tandem gene duplication in the evolution of large gene families in Arabidopsis thaliana. BMC Plant Biol. 2004, 4, 10. [CrossRef]

47. Schaper, E.; Anisimova, M. The evolution and function of protein tandem repeats in plants. N. Phytol. 2015, 206, 397-410. [CrossRef] [PubMed]

48. Sudhir, K.; Glen, S.; Li, M.; Christina, K.; Koichiro, T. MEGA X: Molecular evolutionary genetics analysis across computing platforms. Mol. Biol. Evol. 2018, 6, 1547-1549.

49. Liu, Y.S.; Wang, Y.Z.; Pei, J.B.; Li, Y.D.; Sun, H.Y. Genome-wide identification and characterization of COMT gene family during the development of blueberry fruit. BMC Plant Biol. 2021, 21, 5. [CrossRef] [PubMed]

50. Louie, G.V.; Bowman, M.E.; Tu, Y.; Mouradov, A.; Spangenberg, G.; Noel, J.P. Structure-function analyses of a caffeic acid O-Methyltransferase from perennial ryegrass reveal the molecular basis for substrate preference. Plant Cell. 2010, 22, 4114-4127. [CrossRef] [PubMed]

51. Yoo, J.H.; Seong, E.S.; Ghimire, B.K.; Heo, K.; Jin, X.L. Establishment of Miscanthus sinensis with decreased lignin biosynthesis by Agrobacterium-mediated transformation using antisense COMT gene. Plant Cell. 2018, 133, 359-369. [CrossRef]

52. Pellegrini, L.; Geoffroy, P.; Fritig, B.; Legrand, M. Molecular Cloning and Expression of a New Class of Ortho-Diphenol-OMethyltransferases Induced in Tobacco (Nicotiana tabacum L.) Leaves by Infection or Elicitor Treatment. Plant Physiol. 1993, 103, 509-517. [CrossRef] [PubMed]

53. Heath, R.; Huxley, H.; Stone, B.; Spangenberg, G. cDNA cloning and differential expression of three caffeic acid Omethyltransferase homologues from perennial ryegrass (Lolium perenne). J. Plant Physiol. 1998, 153, 649-657. [CrossRef]

54. Chung, N.; Zhang, X.D.; Kreamer, A.; Locco, L.; Kuan, P.F.; Bartz, S.; Linsley, P.S.; Ferrer, M.; Strulovici, B. Median Absolute Deviation to Improve Hit Selection for Genome-Scale RNAi Screens. J. Biomol. Screen. 2008, 13, 149-158. [CrossRef] [PubMed]

55. Li, C.; He, Q.; Zhang, F.; Yu, J.; Li, C.; Zhao, T.; Zhang, Y.; Xie, Q.; Su, B.; Mei, L. Melatonin enhances cotton immunity to Verticillium wilt via manipulating lignin and gossypol biosynthesis. Plant J. 2019, 100, 784-800. [CrossRef] [PubMed]

56. Robin, A.Y.; Giustini, C.; Graindorge, M.; Matringe, M.; Dumas, R. Crystal structure of norcoclaurine-6-O-methyltransferase, a key rate-limiting step in the synthesis of benzylisoquinoline alkaloids. Plant J. 2016, 87, 641-653. [CrossRef] [PubMed]

57. Zou, X.; Zhen, Z.; Ge, Q.; Fan, S.; Liu, A.; Gong, W.; Li, J.; Gong, J.; Shi, Y.; Wang, Y. Genome-wide identification and analysis of the evolution and expression patterns of the cellulose synthase gene superfamily in Gossypium species. Gene 2018, 646, 28-38. [CrossRef]

58. Tuttle, J.R.; Nah, G.; Duke, M.V.; Alexander, D.C.; Haigler, C.H. Metabolomic and transcriptomic insights into how cotton fiber transitions to secondary wall synthesis, represses lignification, and prolongs elongation. BMC Genom. 2015, $16,477$. [CrossRef] [PubMed]

59. Al-Ghazi, Y.; Bourot, S.; Arioli, T.; Dennis, E.S.; Llewellyn, D.J. Transcript profiling during fiber development identifies pathways in secondary metabolism and cell wall structure that may contribute to cotton fiber quality. Plant Cell Physiol. 2009, 50, $1364-1381$. [CrossRef] [PubMed]

60. Fan, L.; Shi, W.J.; Hu, W.R.; Hao, X.Y.; Wang, D.M.; Yuan, H.; Yan, H.Y. Molecular and biochemical evidence for phenylpropanoid synthesis and presence of wall-linked phenolics in cotton fibers. J. Integr. Plant Biol. 2009, 51, 626-637. [CrossRef]

61. Feng, H.; Li, X.; Chen, H.; Deng, J.; Zhang, C.J.; Liu, J.; Wang, T.; Zhang, X.Y.; Dong, J.L. GhHUB2, a ubiquitin ligase, is involved in cotton fiber development. J. Exp. Bot. 2018, 69, 5059-5075. [CrossRef] [PubMed]

62. Han, L.B.; Li, Y.B.; Wang, H.Y.; Wu, X.M.; Li, C.L.; Luo, M.; Wu, S.J.; Kong, Z.S.; Pei, Y.; Jiao, G.L.; et al. The dual functions of WLIM1a in cell elongation and secondary wall formation in developing cotton fibers. Plant Cell. 2013, 25, 4421-4438. [CrossRef] [PubMed]

63. Ni, W.; Fahrendorf, T.; Balance, G.M.; Lamb, C.J.; Dixon, R.A. Stress responses in alfalfa (Medicago sativa L.). XX. Transcriptional activation of phenylpropanoid pathway genes in elicitor-induced cell suspension cultures. Plant Mol. Biol. 1996, 30, 427-438. [CrossRef] [PubMed]

64. Cui, Y.; BELL, A.A.; Joost, O.; Magill, C. Expression of potential defense response genes in cotton. Physiol. Mol. Plant Pathol. 2000, 56, 25-31. [CrossRef] 